Revista Iberoamericana. Vol. LXII, Núms. 176-177, Julio-Diciembre 1996; 905-923

\title{
LA ESTATUA DE GONZALO GUERRERO EN AKUMAL: ÍCONOS CULTURALES Y LA REACTUALIZACIÓN DEL PASADO COLONIAL*
}

\author{
POR \\ Rolena Adorno \\ Princeton University
}

\section{IMAGINANDO NUESTRO PASADO: CULTURA E HISTORIA EN LOS ÍCONOS CULTURALES}

Uno de los fenómenos más notables asociados con el pasado colonial es que las figuras históricas que lo pueblan son objeto de reflexiones novelísticas y cinematográficas en nuestros días. Aunque en un momento dado hubo quienes quisieron atribuir esta actividad creativa al deseo de aprovechar las oportunidades comerciales ofrecidas por el Quinto Centenario, al aproximarnos al fin de la década ( $y$ del siglo) es evidente que no nos podemos deshacer de las múltiples imágenes de Colón, Las Casas, Cabeza de Vaca y Lope de Aguirre que circulan el día de hoy entre un público internacional. Autores como Carpentier, García Márquez y Abel Posse dan constancia del hecho de que nuestras imágenes de las conquistas y colonizaciones en América no se pueden explicar en base a la conmemoración histórica de algún centenario sino que corresponden a inquietudes perennes y profundas desarrolladas en una larga tradición de reflexiones sobre la identidad y los orígenes de la América contemporánea.

Cuando hablo de estos autores y de las ideas que han hecho circular sobre estos procesos, pienso en un medio limitado y al mismo tiempo difuso de comunicación constituido por los ámbitos privilegiados de autoridades políticas, culturales, sociales y económicas de América y la comunidad internacional. El lugar por excelencia en el cual estas cuestiones son ventiladas es el de los medios de comunicación masiva, trátese de películas, documentales, reseñas de libros, ensayos, notas educativas o culturales, novelizaciones históricas, días festivos o actos públicos. Aunque las distintas fronteras históricas, políticas y culturales introducen variantes regionales y temporales, existe de todos modos un espacio de diálogo internacional en que se comparten distintos problemas, relatos e interpretaciones.

Excluyo como objeto de mi análisis los textos que formulan una comprensión razonada de los grandes procesos histórico-culturales de la colonización de América. Mi objetivo es establecer la formación y el funcionamiento de los relatos o fragmentos de relatos que sintetizan los conocimientos vagos, inciertos y construidos que de un modo $\mathrm{u}$ otro

\footnotetext{
* Quisiera agradecer a Cristián Roa-de-la-Carrera por la perspicacia de su lectura de la primera versión de este trabajo y por su ayuda en dar forma al presente.
} 
constituyen nuestras imágenes acerca de esos procesos. En el mundo actual académico, y en este artículo, la investigación de estos relatos forma parte de un campo de estudios que introduce factores adicionales (por ejemplo, metodológicos y teóricos) al valor de difusión general de estos relatos.

En este trabajo me interesa la creación y circulación del relato de Gonzalo Guerrero, tal como ha sido contado desde el siglo dieciséis y reutilizado en la estatua de Gonzalo Guerrero con el propósito de construir una imagen que armonice los elementos conflictivos que desde el punto de vista lingüístico, político, cultural y económico tienen lugar en Yucatán. He escogido la estatua creada en 1974 como ejemplo porque en ella este relato con sus varios niveles de lectura se elabora como un pacto social entre las autoridades del gobierno central y los habitantes de la península. ${ }^{1}$ Este relato se encuentra destinado a la lectura tanto de los habitantes de la región (con sus propias variantes y divergencias) como de autoridades políticas mexicanas, medios de comunicación masiva y turistas. Por centrarme en el ámbito privilegiado de la producción y relectura de la imagen de Gonzalo Guerrero, no discuto su recepción local (problemática por muchas razones).

Me centro en el relato de Gonzalo Guerrero por dos razones: primero, porque se ha elaborado un gran número de textos literarios e interpretativos sobre su figura en los últimos veinte años. ${ }^{2}$ Segundo, porque es el mejor ejemplo de la formación de un ícono cultural de acuerdo con los principios que voy a anunciar a continuación. Al hablar de "íconos culturales" (esto es, supuestas representaciones de una esencia cultural), pienso en imágenes originadas a partir de un caso histórico y que satisfacen una necesidad primeramente social de definir, explicar, interpretar y proponer los modos ideales de comportamiento en una realidad dada. Mi pregunta al respecto es cómo se originan y consolidan esas imágenes, es decir, cómo son escogidas y elaboradas de tal manera que, siglos más adelante, retengan o cobren una función social.

${ }^{1}$ El lema que acompaña el conjunto escultórico de Akumal, Quintana Roo, anuncia: “Gonzalo Guerrero de Palos de Noguer, España, marinero quien en 1511 naufragó cerca de este lugar casó con una noble maya de nombre Xzazil creando la primera familia de mestizaje nacional".

${ }^{2}$ Entre estas publicaciones señalamos Gonzalo de Guerrero, padre del mestizaje iberoamericano del periodista Mario Aguirre Rosas (México, 1975); Gonzalo Guerrero, novela histórica de Eugenio Aguirre (México, 1980), que ganó en 1981 una medalla de plata de la Academia Internacional del Lutece en París; Gonzalo Guerrero, el primer aliado de los mayas de Salomón González-Blanco Garrido (México, 1991); Conquistadores de Yucatán: La desaparición de Gonzalo Guerrero en la serie "Relatos del Nuevo Mundo" publicada por la Sociedad Estatal Quinto Centenario (Madrid, 1992); Historias de la conquista del Mayab, 1511 -1697 de Fray Joseph de San Buenaventura (Mérida, 1994); y Gonzalo Guerrero, memoria olvidada del periodista Carlos Villa Royz (México, 1995). Los libros de Aguirre Rosas y de San Buenaventura pretenden ser las memorias autobiográficas del propio Gonzalo Guerrero, originalmente escritas sobre papel europeo y pieles de venado (Aguirre Rosas 66; San Buenaventura 9; Solís y Bracamonte xiv). El resto se trata de ficcionalizaciones en base al personaje histórico; dentro de esta categoría, el libro de González-Blanco Garrido y la versión en caricatura titulada Conquistadores de Yucatán aparentan dirigirse a un público de lectores juveniles. Fuera de México, podemos recordar las reflexiones de Tzvetan Todorov en 1982 acerca de Gonzalo Guerrero en La conquista de América y de Hugh Thomas en Conquest: Montezuma, Cortés, and the Fall of Old Mexico de 1993. 
Las prácticas narrativo-interpretativas por medio de las cuales estos íconos son elaborados nos son familiares por su analogía con las formas del conocimiento que hemos practicado desde la niñez: sacar deleite o lección de los cuentos de hadas, las parábolas bíblicas, las fábulas de Esopo, los episodios nacionales y otras narraciones que nos hayan llegado. Se trata de historias con un valor épico (en el sentido de que presentan un saber útil para el individuo como parte de una colectividad) y que al mismo tiempo presentan una situación de alcance individual. Aplicadas al relato de un caso histórico, estas prácticas resultan ser peculiarmente propias para la discusión de temas de interés colectivo. Es necesario aclarar que no se trata simplemente de que en la lectura se asigne un valor ejemplar a los acontecimientos de la vida de ciertos personajes para universalizar los contenidos del relato, pues eso se podría afirmar de casi toda narración sin que se esté hablando de un ícono cultural. Más bien se trata de que el propio relato plantee las preguntas y los problemas que ocupan a una colectividad.

Se observa con claridad este principio en la acogida crítica de la película "Cabeza de Vaca", dirigida por el cinematógrafo mexicano Nicolás Echevarría. ${ }^{3}$ La historia de Cabeza de Vaca ofrece un referente en el cual una empresa con objetivos de dominación política y explotación económica se transforma en un drama personal de sobrevivencia y adaptación en el medio indígena, transmitiendo de este modo un saber que abre la conciencia del dominador a sus propias deficiencias y los peligros que le amenazan. Este relato presenta una noción de redención que sería posible en el encuentro utópico entre las dos partes en conflicto, lo que aparece ejemplificado por la experiencia de Cabeza de Vaca.

Aunque la película recibió reseñas desfavorables en El País y el New York Times, ${ }^{4}$ los comentarios de los críticos revelan el interés que para el público actual tienen no sólo la imagen de Cabeza de Vaca sino las de otros personajes históricos semejantes convertidos en íconos culturales. El crítico de El País llamó la experiencia de Cabeza de Vaca "una de las más esforzadas hazañas personales de que hay noticia" y "una de las aventuras personales más sorprendentes de una aventura colectiva plagada de sucesos hoy casi inconcebibles, a causa de la colosal magnitud del esfuerzo, del horror, de la inventiva, del coraje y de la sanguinaria violencia de sus protagonistas". En el New York Times Vincent Canby describió "Cabeza de Vaca" como la evocación de un sujeto épico en las escalas personal y humana

\footnotetext{
${ }^{3}$ Esta película fue una co-producción del Instituto Mexicano de Cinematografía, Televisión Española y Canal 4 de Inglaterra en el año 1990; el guión lo escribieron Echeverría y Guillermo Sheridan. Cabeza de Vaca, el conquistador sin armas, fue un paradigma de alianza importante en un Quinto Centenario con una España no hace mucho incorporada a la Comunidad Europea y una Latinoamérica saliendo de una época de dictaduras y presentándose como la nueva frontera económica.

${ }^{4}$ Las críticas se refieren a los aspectos artísticos de la película y no al carácter o el relieve de la figura de Cabeza de Vaca. Fernández Santos comentó que "Echevarría ... es incapaz de un mínimo de verosilimitud. De ahí que no logre una ficción, sino su contrario: un fingimiento, una simulación.... Todo parece transcurrir alrededor de un solo árbol y de una sola hectárea de mala llanura" (El Pais, Madrid, 25/2/91). Vincent Canby afirmó que "“Cabeza de Vaca' is a road movie set in a time before there were roads.... There seem to be mountains on the coast of Florida, and Texas would appear to be only a stone's throw from the Pacific coast of Mexico..." (New York Times, Nueva York, 23/3/ 1991).
} 
en general. En referencia a Álvar Núñez Cabeza de Vaca, Beatriz Pastor (244) acertó al caracterizar su narración como "la transformación de una expedición fracasada en vivencia personal de la problemática de toda una época". De modo que la relación entre lo épico y lo personal no consiste en el privilegio de ninguna de estas dimensiones sino en un arreglo que conserve ambas presentando un tema de dimensión épica a través del caso de un individuo. Al hacer convivir lo épico y lo personal este tipo de relato hace posible la clase de lectura utilitaria que ejemplifica el proceso que he venido describiendo: el funcionamiento de los íconos culturales.

¿Cómo se logra y se mantiene un balance entre lo particular e histórico del caso individual y la grandeza colectiva de los acontecimientos cuyas consecuencias cobran una dimensión muy por encima de la particularidad de un solo sujeto? ¿Cuáles son los elementos narrativos que permiten convertir al relato de una experiencia personal en un objeto de interpretaciones variadas e inacabables para satisfacer el interés común? ¿Cómo transformar un evento histórico en un drama humano de gran alcance? Las respuestas a estas interrogantes se encuentran en los relatos de personajes históricos que son convertidos en emblemas fundacionales de la cultura latinoamericana.

Los íconos culturales suelen producirse y perpetuarse no tanto como casos particulares de un momento histórico o imágenes de las figuras individuales que en ellos participan, sino como la representación de contenidos culturales a través de estos casos y personajes. Estos íconos son comunicados mediante diversas variaciones y reescrituras en las cuales ciertos rasgos claves se mantienen siempre reconocibles. La operación del receptor consiste en establecer y mantener un equilibrio entre los principios básicos que retienen el carácter épico del relato y las particularidades que constituyen el caso concreto.

Creo que esto ocurre por dos razones. Primero, buscamos una experiencia humana y real sobre la que queremos saber cómo se llevó a cabo. Es decir, buscamos anclar ese saber épico en algo concreto. Segundo, deseamos llenar los vacíos en el relato de acuerdo con un prisma cultural con el propósito de satisfacer nuestras necesidades como intérpretes de los acontecimientos - necesidades motivadas no por el afán de completar una historia sino por responder a las inquietudes colectivas que creemos esa historia sea capaz de iluminar. Esto último es lo que conduce a la reinvención y reescritura de los mismos acontecimientos. En la medida en que el acto de narrar permite tomar una posición, explicar un hecho o atribuir significados sin que sea necesario adoptar una actitud confrontacional o propagandística, la inclinación natural es aprovechar esta ilusión para construir imágenes que inadvertidamente porten una visión determinada.

Teniendo presente la salvedad de que las prácticas de lectura varían con el tiempo y que la exposición a las prácticas de comunicación contemporánea crean una actitud mucho más suspicaz de parte del receptor (acostumbrado a encontrar mensajes codificados dentro de otros mensajes y no esperar nada gratuito, como en la publicidad), podemos asumir que con ciertas variantes el funcionamiento de los íconos culturales mantiene las características fundamentales ya señaladas. Lo que estos íconos nos ofrecen en el presente consiste en lo siguiente: satisfacer el deseo de narrar una vez más la misma historia no para conocer sino para reconstruir lo que es irrecuperable en nuestros perdidos orígenes culturales. La ilusión es que recreando los orígenes vamos a ser capaces de reactualizar nuestra identidad cultural 
de un modo más perfecto por ser más cercano a su estado prístino, es decir, no vista en relación con la cultura real como la recreamos cada día sino como su orden trascendente.

\section{La estatua de GonZalo Guerrero}

El siguiente retrato de Gonzalo Guerrero y su familia maya aparece en un folleto publicado por el Club de Yates Akumal Caribe, en la ocasión de su inauguración en enero de 1975 por CEDAM International (Club de Exploraciones y Deportes Acuáticos de México):

Gonzalo contempla el mar; el viento del Caribe juega con su cabello. El es marinero y esparce su vista en una mezcla de melancolía y desafío... Los chalchihuites no se relacionan en nada con lo que usaba al salir del puerto de Palos. Ya no es uno sino que está ligado con amorosas ataduras a los hijos de la unión con la noble maya que tranquila y serena dirige a él la mirada mientras amamanta al más pequeño de sus críos.... Cierra el conjunto la pequeña que, sin saber su origen, juega con el viejo casco de su padre.... Ella está al sol, al aire y al agua. Nació libre y feliz. Tiene padre y madre que la protejan y pertenece al mundo que la rodea.

De este modo útopico y ajeno a su contexto el autor anónimo interpreta el conjunto escultórico de Gonzalo y su familia (figura 1) que recibe a los que llegan al pueblo de

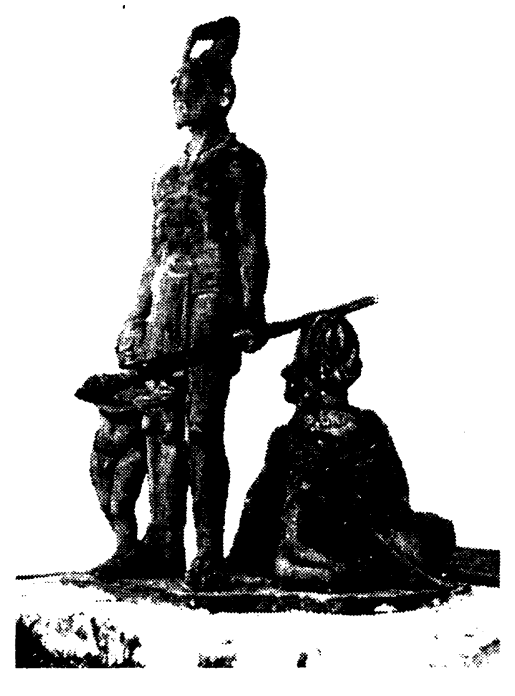

Figura 1: El conjunto escultórico de Gonzalo Guerreroy su familia maya en Akumal, Quintana Roo, México. Fotografia: Rolena Adorno. 
Akumal, ubicado a 105 kilómetros de Cancún en la playa caribeña de Quintana Roo. El personaje principal es el español náufrago que llegó a la península de Yucatán en 1511, conocido por el nombre de Gonzalo Guerrero. Sentada en el suelo y mirando por detrás a su esposo, la noble maya amamanta a una recién nacida criatura (figura 2); un poco más

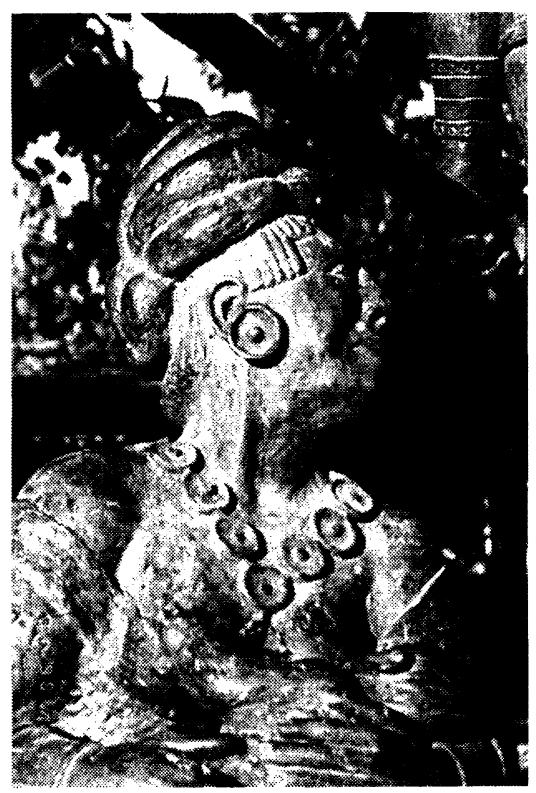

Figura 2: La parte superior de la estatua de la noble maya, esposa de Gonzalo Guerrero. Fotografía: Rolena Adorno.

adelante y a la izquierda de Gonzalo está su niña (véase figura 1), jugando con el casco del padre que "es para ella en medio de sus fantasías, bajel de sueños que toda niña sueña". Adelante, se encuentra Gonzalo erquido con su lanza, y a su derecha, su hijo mayor, "inocente de la inminente caída de los suyos ante la fe extranjera impuesta con sangre humana", abraza la pierna del padre.

El conjunto escultórico lo creó el artista Raúl Ayala Arellano entre marzo y agosto de 1974 en su taller de Ciudad Juárez, Chihuahua. El escultor preparó por lo menos dos fundiciones del conjunto; ambas se encuentran en México: la de Akumal, en el estado de Quintana Roo, junto al Club de Yates y la otra ocupa una glorieta en la prolongación del Paseo Montejo en la ciudad de Mérida, Yucatán. (Una tercera estatua de Gonzalo Guerrero se encuentra en la capital federal, pero no he podido verificar que se trate de la misma.) Trabajo con la de Akumal porque, según se sabe, el Gonzalo histórico (1511-34) se integró 
a la vida de una comunidad maya ubicada a más de 250 kilómetros al sur de Akumal en la provincia de Chetumal. Respecto a este Gonzalo, no existe ninguna fuente directa totalmente confiable; la fuente original es la información oral ofrecida por Jerónimo de Aguilar a Hernán Cortés en Cozumel en la primavera de 1519, y sólo en años recientes se han publicado dos versiones muy diferentes de memorias que se le atribuyen (Aguirre Rosas [1975], San Buenaventura [1994]).

El caso de Gonzalo que nos presenta esta escultura es la ilustración más perfecta del funcionamiento de un ícono cultural: el contraste entre la riqueza interpretativa y la parquedad de datos concretos comprobables. Y estos pocos datos los conocemos sólo de segunda mano, a través de Cortés y otros interlocutores suyos. ${ }^{5}$ Efectivamente, aparte de la confirmación independiente del contador y gobernador de Honduras-Higueras, Andrés de Cereceda, que encontró muerto al que era aparentemente Gonzalo en un campo de batalla en Centroamérica en 1534 (Chamberlain 172n28), el único relato con que contamos es el de Aguilar transmitido por boca de otros (aun no existe documentación suficiente para respaldar la autenticidad de las memorias). ${ }^{6}$

Precisamente porque carecemos de información amplia y precisa acerca de la historia de Gonzalo Guerrero, podemos comprender la necesidad de elaborar recreaciones narrativas para dar un perfil más concreto al personaje histórico (conocido no por su intervención en algún acontecimiento sino por lo intrigante de su caso) y para alcanzar una interpretación que plantee las cuestiones culturales de relevancia en el día de hoy. Debo aclarar que no se trata de un proceso instantáneo; la formación del ícono cultural es producto de la narración, pero no ocurre en la narración. Esta sólo puede proporcionar al lector una motivación por la cual continuar recreando la historia, porque el ícono cobra vida en el acto de ser continuamente reelaborado y no en una construcción conclusa y cerrada.

Al mismo tiempo, queremos insistir en otro principio importante: es lo no conocido y lo indeterminable de su caso lo que fomenta el deseo de darle cuerpo, vida y significado -significados relevantes para nosotros y no respecto al personaje histórico-a través del acto de narrar. Si seguimos este proceso creativo de cerca en la figura de Gonzalo, considerando las (re)elaboraciones principales del caso en el siglo dieciséis, podremos establecer los principios que animan su caracterización y que hoy, cuatro siglos más tarde, hacen posible la reactualización de sus significados. Este caso permite aclarar con precisión

\footnotetext{
${ }^{5}$ Algunos de éstos eran sus compañeros en la conquista (Bernal Díaz, Andrés de Tapia) y otros, historiadores que tuvieron contacto personal con Cortés más adelante (Francisco López de Gómara, Juan Ginés de Sepúlveda y Francisco Cervantes de Salazar).

${ }^{6}$ En cuanto a las memorias de la versión de San Buenaventura, los doctores Hanns J. Prem y Berthold Riege y su colega Antje Gunsenheimer ("En torno" 4), antropólogos de la Universidad de Bonn, niegan la autenticidad del manuscrito y afirman que "el autor de la relación de fray Buenaventura debe haber vivido en el presente siglo y posiblemente sigue estando entre nosotros". Inmediatamente a continuación se publicó la réplica de Gabriela Solís Robleda ("En torno" 5), quien editó la obra de San Buenaventura junto con Pedro Bracamonte y Sosa, en la cual defiende la autenticidad del manuscrito. Aunque ha habido una argumentación intensa por ambas partes, tiendo a inclinarme por la duda a causa de la existencia de otras supuestas memorias de Gonzalo publicadas por Aguirre Rosas. El hecho de que ambas ediciones se contradigan indica los problemas que presentan estos textos.
} 
los procesos interpretativos generadores de íconos culturales y dilucidar las causas de la vigencia de una temática histórica lejana dentro de un contexto de actualidad.

Antes de trazar en detalle la emergencia y la consolidación de las narraciones que han llegado a producir el ícono cultural de Gonzalo Guerrero, quiero señalar dos hechos importantes que apuntan a la debilidad histórica de la información disponible: el apellido "Guerrero" no aparece en las narraciones de su caso hasta la publicación de la Historia general de las Indias de Francisco López de Gómara en 1552 (otros testimonios anteriores contienen nombres distintos) y el testimonio de Jerónimo de Aguilar de su encuentro con Guerrero se contradice con dos fuentes de primera mano y un autor que conocía muy bien la región de Yucatán, quienes indican que Aguilar no llegó a contactar a Gonzalo al recibir en 1519 la noticia de que una expedición de españoles les buscaba. ${ }^{7}$

Al señalar estas discrepancias, mi interés no es debatir la veracidad de los acontecimientos sino destacar la precariedad de las fuentes precisamente por ofrecer un material de plasticidad suficiente para moldear y remoldear sus contenidos con el prestigio de lo histórico.

\section{LA EMERgENCIA DE LA FiguRA DEL ESPAÑOl CAUTIVO Y SU FUga CULTURAL}

Elnúcleo de la historia de Gonzalo Guerrero considera el encuentro de Cortés con Aguilar, el intento del último de localizar y traer a Gonzalo de vuelta con los españoles y la negativa de Gonzalo a regresar. Las variantes más importantes se relacionan con las razones que lo motivaron a quedarse entre los mayas. De Gonzalo Guerrero sólo se tiene la certidumbre de su relevante decisión de permanecer, en torno a la cual se ha construido su carácter de ícono cultural.

La primera referencia a los españoles náufragos y cautivos en Yucatán se encuentra en las instrucciones del gobernador de Cuba, Diego Velázquez, fechadas el 23 de octubre de 1518 y dirigidas a Hernán Cortés, para ir en socorro de la armada de Juan de Grijalva y la carabela que Velázquez había enviado en su busca. Entre los encargos que Velázquez dio a Cortés, le insistía que intentara "por todas las vías e maneras e mañas que ser pudiere por haber a los dichos cristianos por rescate o por amor o por otra cualquier vía donde no intervenga detrimento dellos ni de los españoles que lleváis ni de los indios" (Martínez ed. $48,53)$.

El primer relato de lo que Cortés y los suyos encontraron en Yucatán en la primavera de 1519 es la carta del cabildo de Veracruz. Lo importante en esta primera relación del encuentro es la declaración de que tuvieron contacto sólo con Aguilar y que éste no se habia comunicado con los demás cautivos:

Deste Jerónimo de Aguilar fuimos informados que los otros españoles que con él se perdieron en aquella carabela que dio al través estaban muy desparramados por la tierra, la cual nos dijo que era muy grande y que era imposible poderlos recoger sin estar ni gastar mucho tiempo en ello (Cortés 124).

\footnotetext{
${ }^{7}$ Me refiero, respectivamente, a la carta del cabildo de Veracruz del 10 de julio de 1519 , a la "Información de méritos y servicios" de Andrés de Tapia de 1561 y a la Relación de las cosas de Yucatán (1566) de Fray Diego de Landa.
} 
En esta carta Gonzalo no aparece en el escenario. El estreno de Gonzalo ocurre en el interrogatorio presentado por Hernán Cortés (1534) para su defensa en el juicio de residencia iniciado en 1526 al llegar a Nueva España el juez Luis Ponce de León (Martínez 898). ${ }^{8}$ Lo significativo de todo esto es que la decisión de Gonzalo de quedarse entre los mayas es relevante para interpretar la historia más de una década después de la conquista de México cuando los primeros intentos de conquistar Yucatán (donde se había pensado que Gonzalo había participado en defensa de los mayas) se encontraban todavía frescos en la memoria de las autoridades de Nueva España.

El de Cortés es el primer testimonio que ofrece el perfil del personaje histórico que conoceremos más adelante por el nombre de Gonzalo Guerrero, y que normalmente no es tomado en cuenta en los resúmenes de los relatos de la historia de Gonzalo. ${ }^{9}$ Aquí Cortés recuerda lo que le dijo Aguilar acerca del otro cautivo en Yucatán (CDI 27: 319-23): que muchos de los náufragos habían muerto en la travesía y que ocho o nueve llegaron a Yucatán pero en tan malas condiciones que "si los yndios no los remediaran, no escapara nenguno; e ansí murieron todos, ecebto dos" (CDI 27: 322). Cortés los identifica como "Gerónimo de Aguilar, el uno, y el otro, un Morales, el qual no abía querido venir, porque ternía ya oradadas las orexas, y estaba pintado como yndio, e casado con una yndia, y ternía hixos con ella" (CDI 27: 322-23).

Es en este documento que Hernán Cortés presenta por primera vez la historia del cautivo, ya entonces libre, a quien llama "un Morales" y cuyos lazos familiares mayas y mestizos explican que no se incorpore a la empresa conquistadora de Cortés.

Posterior al testimonio de 1534, la carta del gobernador Andrés de Cereceda de 1536 aparentemente anuncia su muerte (Torres Ramírez 385, 386), llamándole "Gonzalo Azora", o en otras transcripciones "Gonzalo Aroça" (Tozzer ed. 8n38). En el valle del Río de Ulúa en 1534, Pedro de Alvarado atacó la fortificación principal del cacique Ciçumba; en esta ocasión se supone que Gonzalo Guerrero habría llevado tropas mayas para socorrer al cacique (Chamberlain 172). Dos años más tarde en su informe al emperador Cereceda afirmaba que "con un tiro de arcabuz se había muerto un cristiano que se llamaba Gonzalo Azora, que es el que andaba entre los indios en la provincia de Yucatán veinte años ha y más" (citado en Torres Ramírez 386). Y esto ha bastado entre los historiadores para establecer la identidad entre Azora, Morales y Guerrero, que aparece en un momento posterior.

${ }^{8}$ Es Thomas (678n34) quien menciona el testimonio de Cortés en 1534 como una fuente para la historia de Gonzalo. Según Martínez (574), la confección del documento relevante se debe al propio Cortés, que "debió dedicarse varios meses a elaborar los dos interrogatorios", para los cuales "puede suponerse que contó con el auxilio de algunos de sus capitanes y soldados que tuvieran la memoria más fresca respecto al cúmulo de acontecimientos ocurridos lustros atrás". El interrogatorio al cual pertenece la información que Cortés presenta (en forma de preguntas) sobre nuestro personaje abarca los hechos públicos de Cortés desde la salida de su expedición de Cuba en 1518 hasta el mismo año de 1526. La transcripción de los interrogatorios para los testigos de cargo sólo ha sido publicada en la Colección de documentos inéditos (CDI 27: 301-569 y 28: 388-429).

9 Estos resúmenes (i.e., Lipschutz, Martínez Marín, Torres Ramírez) comienzan con fuentes posteriores como Gonzalo Fernández de Oviedo o Bernal Díaz del Castillo. 


\section{La presentación de Gonzalo, "Guerrero"}

Quizás por estar informado de la incertidumbre del nombre de este protagonista, Oviedo (3: 232-34; lib. 32, cap. 3), al redactar en 1542 su relato sobre la conquista de Yucatán para su Historia general y natural de las Indias, lo llama sencilla y prudentemente "un Gonzalo, marinero". Lo novedoso de su interpretación del personaje es que presenta al español asimilado como un importante líder militar entre los mayas y le culpa por el fracaso del primer intento (en 1528) del adelantado Francisco de Montejo y su teniente, el capitán Alonso Dávila, de conquistar la provincia de Chetumal, una zona del este de Yucatán provechosa por su "buen río y disposición" (Oviedo 3: 234; lib. 32, cap. 3). Haciendo uso de sus graciosos comentarios lingüísticos, Oviedo escribe que el adelantado llegó "bien ochenta leguas de aquella Salamanca a un pueblo de la costa que se dice Chitemal, e conforme a su última sílaba mal subçedió todo lo de allí” (3: 232; lib. 32, cap. 3).

Los primeros elementos del ícono de Gonzalo comienzan a aparecer en la historia de Oviedo, quien pone de relieve su infidelidad a los españoles al rechazar una tentadora oferta de Montejo. Oviedo (3: 233; lib. 32, cap. 3) cuenta que como "hombre hijodalgo" Montejo prometió favorecer y honrar a Gonzalo haciéndole "de los principales hombres uno de los más escogidos e amados que en estas partes oviere"; Gonzalo supuestamente respondió, escribiendo con carbón en las espaldas de la carta: "Señor, yo besso las manos de vuestra merçed: e como soy esclavo, no tengo libertad, aunque soy cassado e tengo muger e hijos, e yo me acuerdo de Dios; e vos, señor, e los españoles, terneys buen amigo en mí". Vale la pena notar que si se conociera el paradero de esta carta éste sería el único elemento sólido que tendríamos para reconstruir la historia de Gonzalo; por otra parte, es revelador que Oviedo nos presente no el rechazo de Gonzalo a Cortés en 1519 sino su respuesta a Montejo en 1528 con los mismos argumentos que se nos dice habría usado nueve años antes.

En el relato de Oviedo, Gonzalo no sólo dio guerra a los españoles después de rechazar por carta la invitación del adelantado de incorporarse a los conquistadores, sino que confeccionó un ardid gracias al cual Dávila y los suyos abandonaron Chetumal: convenció a Dávila de que el adelantado Montejo y todos los que con él iban en la carabela estaban muertos; simultáneamente, Guerrero convenció a Montejo y los suyos de que Dávila y su compañía habían perecido (Oviedo 3: 233-34 [lib. 32, cap. 3]; Tozzer ed. 49-50n250). Sólo después de haber continuado sus exploraciones hasta treinta leguas de Honduras y el Río de Ulúa, el adelantado Montejo volvió a la isla de Cozumel para descubrir que Dávila y los suyos estaban vivos, y "se abraçaban con mezcladas lágrimas de goço" (Oviedo 3: 234; lib. 32, cap. 3).

El gozo seguramente ocultaba la humillación que los dos capitanes habrían sentido al verse burlados por el ex-marinero Gonzalo. Con esta nota irónica se cierra en 1528 el proceso que se ha llegado a conocer como "la primera fase de la conquista de Yucatán" (Chamberlain 35; Tozzer ed. 50n250). En efecto, para Oviedo (3: 227-32), "Gonzalo, marinero" fue la causa del fracaso de ese intento. En 1531, y a pedidos del adelantado Montejo, Alonso Dávila emprendió una segunda expedición de conquista a Chetumal (Chamberlain 100). Según Oviedo, Dávila tenía como propósito el "castigo de aquel infiel marinero y a la rebelión e alçamiento de los indios" (3: 244, 246; lib. 32, cap. 6). Dávila y los suyos atacaron al señor de Chetumal "sin ser sentidos e mataron muchos dellos, e 
prendieron más de sessenta personas, y perdieron un caballo, que les mataron de una lançada.... Preguntando a los presos por aquel bellaco mal chripstiano Gonçalo, marinero, dixeron que era muerto, e assi era verdad" (Oviedo 3: 246; lib. 32, cap. 6). A pesar de que la muerte de Gonzalo habría ocurrido tres años más tarde en 1534, según el testimonio de Cereceda, el interés de lo dicho por Oviedo es que lo identifique a Gonzalo como responsable por las dificultades continuas que Alonso Dávila experimentaba en la conquista del sureste de Yucatán (Tozzer ed. 8n38). ${ }^{10}$

Oviedo nos da el primer retrato de Gonzalo no sólo "marinero" sino además "guerrero", marcando así un primer momento en la formación de este ícono cultural." Lo que hace Oviedo es presentar su juicio de la conducta de este Gonzalo "ya convertido en indio, e muy peor que en indio, e casado con una india e sacrificadas las orejas e la lengua, e labrada la persona pintado como indio, e con muger e hijos". Luego agrega: "Bien es de creer que los tales no podían ser sino de vil casta e viles heréticos" (Oviedo 3: 232-33, 259 [lib. 32, cap. 3; lib. 33, cap. 1]).

Oviedo, como lector y narrador de la historia de Gonzalo "guerrero", selecciona, organiza y refunde la constelación de elementos que para su época y las posteriores va a constituir su imagen. Impone un sello personal a la construcción de este ícono al explicar la decisión de Gonzalo por razones de pureza de sangre, es decir, al sugerir que no provenía de una familia de cristianos viejos. En el fondo, para Oviedo la traición moral de Gonzalo sólo puede explicarse en base a su supuesta infidelidad religiosa y espiritual heredada. Demás está señalar la importancia que la pureza de sangre tenía como tema cultural para la España del siglo dieciséis; sin duda esto es lo que llevó a la formación del ícono cultural de Gonzalo en la historia de Oviedo.

\section{La CONSOlidación de la figura de Gonzalo Guerrero}

Puesto que la sección que he discutido de la historia de Oviedo no se publicó hasta mediados del siglo diecinueve, es a Francisco López de Gómara a quien atribuimos la cristalización del ícono cultural de Gonzalo Guerrero en su muy leída Historia de las Indias y la conquista de México. Casi dos décadas después de la muerte del español náufrago, Gómara lo bautiza de acuerdo con la imagen que circulaba entre los participantes y relatores de la guerra de la conquista de Yucatán, al presentarlo del siguiente modo: "Gonzalo Guerrero, marinero, que está con Nachancán, señor de Chetemal, el cual se casó con una rica señora de aquella tierra, en quien tiene hijos, y es capitán de Nachancán, y muy estimado por las victorias que le gana en las guerras que tiene con sus comarcanos" (Gómara, Conquista 26 [cap. 12]; ver Gómara, Historia 77 [cap. 53]).

\footnotetext{
${ }^{10}$ Chamberlain (104) responsabilizó a Gonzalo por el ataque a Dávila en 1531 en Chequitaquil y el levantamiento de toda la provincia de Uaymil-Chetumal poco después.

${ }^{11}$ Posteriormente Bernal Díaz (54, 55; caps. 29 y 30) atribuiría a Gonzalo una intervención en los ataques contra la expedición de Francisco Hernández de Córdoba en Cotoche en 1517 y contra la de Juan de Grijalva en Champotón en 1518. Sin embargo, esto es improbable por haberse producido estos ataques tan lejos de la provincia de Chetumal donde Gonzalo vivía (Tozzer ed. 8n38; Thomas $678 \mathrm{n} 34)$.
} 
Al narrar la versión más completa (o por lo menos, más lograda) de la historia de Gonzalo Guerrero, Gómara (Conquista 24-26; caps. 11-12) agrega a lo ya sabido otros elementos. ${ }^{12}$ Declara que había sólo dos supervivientes españoles en Yucatán en el momento en que Cortés llegó a Cozumel. Pone a Jerónimo de Aguilar relatando el caso en primera persona, el que explica la cuestión de que Guerrero no quisiera volver: "creo que de vergüenza, por tener horadadas las narices, picadas las orejas, pintado el rostro y manos a fuer de aquella tierra y gente, o por vicio de la mujer y amor de los hijos" (Gómara, Conquista 26; cap. 12). Esta declaración reitera y amplifica la de Cortés en 1534 y hace eco también de la de Oviedo en 1542 acerca de las razones por las cuales Guerrero no quiso volver con los cristianos después de ocho años en Yucatán.

La elaboración que hace Gómara de las mutilaciones corporales de Guerrero y de su familia maya logró un gran impacto por la forma en que presenta la decisión del personaje. Gómara retrata la vida doméstica de Guerrero en Yucatán como un "paraíso pagano" en que la familia juega un papel de importancia primordial en su elección. Utilizo la expresión "paraíso pagano" para referirme a la imagen que presenta Gómara del casamiento, o "el vicio por la mujer" y el amor a los hijos, que parecen tener una cualidad especial en Yucatán ya sea por razones sociales o por la solución que le presentaba al problema de la subsistencia - viviendo apartado de la fe, según lo había afirmado Oviedo con la óptica de la época.

Aunque el amor a una mujer pagana podía verse entonces como vicio, según opina Gómara, el amor a los hijos era un amor desinteresado. De esta manera, podemos decir que para 1552, con la historia de Gómara, una de las líneas de la interpretación de Gonzalo Guerrero quedaba bien establecida: la del español que tenía una vida hecha entre los indios (pecaminosamente no cristiana) al estar casado con una india y con hijos mestizos. Junto al matrimonio y la paternidad - los dos elementos explícitos del relato ya desde CortésOviedo había agregado el elemento del papel militar de Gonzalo y su infidelidad religiosa. Con Gómara se reúnen sólo tres de estos elementos (los de esposo, padre y guerrero) y se excluye el de su pureza de sangre. Este Gonzalo se caracteriza por el amor con que protege a su familia maya y defiende su nueva patria. Entre 1534 (el mismo año de la probable muerte de Gonzalo) y 1552 el relato fundamental se había formado. Estas son las fechas comprendidas entre el testimonio de Cortés y la publicación de la historia de Gómara (es muy probable que éste se haya nutrido de la historia de Oviedo y de la información verbal que recibiera de Cortés en sus tertulias).

\footnotetext{
${ }^{12}$ Estos elementos nuevos, que muchos autores posteriores repetirán, son: 1) el texto de la carta de Cortés a los náufragos/cautivos, 2) el transporte de la carta en los cabellos de uno de los indios mensajeros "para no ser vistos ni barruntados por espías", 3) el nombre (Juan de Escalante) del que capitaneaba el bergantín de rescate, 4) el hecho de que fue la nave del capitán Pedro de Alvarado que corría peligro y forzó el regreso de la expedición a Cozumel, 5) la presencia de Cortés y solo cincuenta hombres más en la isla cuando llegó la canoa con el cautivo, 6) el encargo a Andrés de Tapia para vigilar y recibir la canoa en que llegaba el cautivo, 7) el diálogo de Aguilar con la compañía de Tapia: "Señores, ¿sois cristianos?"..., y 8) la explicación de su naufragio por lo ocurrido en Darién, es decir, "las pasiones y desventuras de Diego de Nicuesa y Vasco Núnez Balboa" (Gómara, Conquista 24-26; caps. 11-12).
} 


\section{Bernal Díaz del Castillo y la nueva problemática cultural del mestizaje}

La reelaboración del relato por Bernal Díaz (Historia verdadera de la conquista de la Nueva España, caps. 27-29) pone de relieve como el ícono cultural se reconfigura de acuerdo con las necesidades del nuevo contexto social generado por sesenta años de colonización y mestizaje. Tal vez por tener un contacto cercano con la realidad del mestizaje, Bernal Díaz fija la dimensión mestiza del personaje de Gonzalo, la cual ha perdurado como la más importante para nuestros días. Bernal Díaz nos hace reflexionar sobre la importancia que el mestizaje tuvo a partir de las primeras décadas de la presencia de los españoles en América.

Bernal aprovecha la técnica empleada por Gómara de usar la primera persona para darle un valor testimonial a la información sobre Gonzalo. Más atrevido que Gómara, Bernal Díaz (50; cap. 27) lo hace en boca del propio Guerrero:

Hermano Aguilar, yo soy casado, y tengo tres hijos, y tiénenme por cacique y capitán quando ay guerras; íos vos con Dios, que yo tengo labrada la cara y oradadas las orejas. ¿Qué dirán de mí desque me vean esos españoles ir desta manera? E ya veis estos mis hijitos quán bonicos son. Por vida vuestra, que me deis desas cuentas verdes que traéis, para ellos, y diré que mis hermanos me las enbían de mi tierra. ${ }^{13}$

Para Bernal Díaz, Guerrero es el pater familias orgulloso por sus hermosos hijos, quien da una bendición cristiana a su compatriota y pide amorosamente las cuentas de vidrio para el único propósito que deben servir: juguetes para niños. Gonzalo ofrece a Bernal Díaz la posibilidad de crear un ícono en el cual el conquistador es transformado en una figura que no se opone a la del "protector de indios", en otras palabras, un español que no requiere de la supervisión y el control de la monarquía para relacionarse con los nativos. Esta presentación del mestizaje cultural por parte de Bernal Díaz representa una dimensión no vista en los relatos anteriores y será la nota interpretativa dominante en nuestros días.

En este "auto-retrato" de Gonzalo Guerrero, su papel "como capitán cuando ay guerras" lo identifica con las construcciones anteriores del ícono. Vimos anteriormente que Bernal Díaz sugiere (aunque atribuye el dato a Jerónimo de Aguilar) que Guerrero fuera el "inventor que nos diessen la guerra que nos dieron y que vino él allí juntamente con un cacique de un gran pueblo, según ya he dicho en lo de Francisco Hernández de Córdoba" (54; cap. 29). Contrastando esta mención de Bernal Díaz con la fuerte condena hecha por Oviedo, se comprende que Bernal, al poner en boca de Gonzalo Guerrero la descripción de su situación doméstica y política, hace un balance en que el abandono de los compatriotas se yuxtapone con el retrato favorable de la creación de una vida familiar y política entre los mayas. Este es el paradigma con que Bernal interpreta la situación política y social del encomendero en su época y lo aplica a la construcción del ícono de Gonzalo Guerrero.

\footnotetext{
${ }^{13}$ Este mismo discurso lo repetirá en 1688 Fray Diego López de Cogolludo en su Historia de Yucatán
} (23; lib. 1, cap. 7). 
VII. LA PERSPECTIVA de los aUtores mestizos, Muñoz CAMARgo(1576) y AlVa IXTLILXochitl $(1615-25)$

Incluyo en este examen de los primeros relatos de Gonzalo Guerrero el de los autores mestizos de la época porque ellos presentan una relectura del mestizaje desde adentro que pone de relieve la complejidad de su situación. No sorprende, entonces, que las interpretaciones que estos autores hicieron de este caso reivindican el mestizaje no por la relación entre españoles e indios sino por su situación conflictiva y sus intereses como mestizos. El primer ejemplo es de la década de 1570 y se trata del relato de Guerrero y Aguilar por Diego Muñoz Camargo en su Historia de Tlaxcala (1576). Aunque remite a la historia de la conquista de México de Bernal Díaz, a quien identifica como un "autor muy antiguo que hablará como testigo de vista copiosamente", Muñoz Camargo (187; lib. 2, cap. 2) no sigue su versión del relato. Al contrario, ofrece una interpretación alucinante de la historia de Aguilar y Guerrero por la reordenación de los papeles que hace de Aguilar y Guerrero para ajustarlo a su visión mestiza.

En primer lugar, el nombre de Gonzalo Guerrero desaparece y se sustituye por el de García del Pilar, personaje con quien compartía semejantes connotaciones negativas. ${ }^{14}$ Sin hacer ningún comentario sobre "el cautivo Pilar," Muñoz Camargo transfiere a Jerónimo de Aguilar los elementos del relato de Gonzalo Guerrero. Es Aguilar quien se convierte en indio y quien se casa - no con una mujer maya sino con la propia Malintzin (luego Doña Marina y más recordada bajo el ícono cultural de La Malinche). En esta versión Malintzin había sido vendida a algunos mercaderes mexicanos, y luego la entregaron como cautiva a Jerónimo de Aguilar, quien también se encontraba cautivo en esa época (Muñoz Camargo 189; lib. 2, cap. 2).

Muñoz Camargo, a pesar de atribuir a Aguilar las características indígenas de Guerrero, lo presenta como leal al mundo cristiano; esto no sólo por su devoción, como afirma el propio Muñoz Camargo, sino porque Aguilar había tomado "órdenes de evangelio" como afirma Bernal Díaz (54; cap. 29). ${ }^{15}$ Lo que hace Muñoz Camargo es diferenciar cultura ("costumbres") de religión con el propósito de eliminar los elementos de infidelidad de la imagen del mestizo.

Posteriormente el texcocano Fernando de Alva Ixtlilxochitl retomó el tema de la pareja Aguilar/Marina. En su Historia de la nación chichimeca, redactada entre 1615 y 1625, Alva Ixtlilxochitl (198; cap. 79) casa a Aguilar con doña Marina después de que ella "se volvió cristiana". Siguiendo la versión de Gómara pero omitiendo el detalle significativo de los hijos, Alva Ixtlilxochitl trata el caso de Gonzalo Guerrero con una sola frase: "y no había

15 Muñoz Camargo (189; lib. 2, cap. 2) escribe sobre Aguilar, dándole las ya conocidas características de Guerrero: "se horadó las orejas y narices y se labró y se rayó la cara y carnes como los propios indios". Aguilar permanece, sin embargo, fiel al culto cristiano: "Compelido de la pura necesidad se puso a todo, aunque siempre y a la continua observó su cristiandad y fue cristiano y guardó el conocimiento y observancia de la ley de Dios".

16 "El nacimiento de dos naturalezas: lo criollo y lo mestizo en Hispanoamérica", 28-29 de marzo de 1996, convocado por la Facultad de Ciencias Antropológicas y organizado por el dr. Alfredo Enríquez Ordóñez, profesor-investigador de dicha facultad. 
quedado más que él y un Gonzalo Guerrero, que se casó en aquella tierra, quien estaba muy rico y no quiso venir con él, porque tuvo vergüenza de que le viesen las narices horadadas al uso de la tierra" (Alva Ixtlilxochitl 196; cap. 78).

Los relatos de los dos autores interesan por sus omisiones: aunque ambos utilizan a Aguilar y a Marina para construir la imagen simbólica de la primera pareja mixta en México, ninguno de los dos autores los presentan como padres. Con Muñoz Camargo, por otra parte, Gonzalo Guerrero desparece por completo y Alva Ixtlilxochitl no discute el caso de Gonzalo Guerrero sino que reduce la presentación de éste a una oración subordinada. Menciona su casamiento pero aparece como un matrimonio sin hijos.

Para los dos autores mestizos, el caso de Guerrero no sólo resultaba ser peligroso porque éste había abandonado su identidad como cristiano (una identidad que ellos seguramente tenían que comprobar con frecuencia en una sociedad hispano-criolla hostil a sus intereses) sino también porque como ícono del mestizaje presentaba su aspecto más conflictivo: siendo los dos autores hijos de madres indígenas, es revelador que supriman a los hijos que los autores anteriores a quienes citaban (Gómara, Bernal Díaz) habían destacado como la razón por la cual Gonzalo había permanecido entre los mayas. Esta omisión nos aclara que el elemento más relevante de la imagen de Gonzalo "infiel y traidor" no era su matrimonio mixto sino su paternidad.

He incluido a Alva Ixtlilxochitl en mi análisis a pesar de salir del marco temporal del siglo dieciséis porque permite explicar retrospectivamente las posibles motivaciones de Muñoz Camargo. Además, tratándose de un ícono cultural referente al mestizaje, es fundamental incluir la visión de los propios autores mestizos. De modo semejante, quisiera agregar algunas palabras sobre Antonio de Solís y Rivadeneira, autor de Historia de la conquista de México (1684), para complementar la visión del ícono en los autores mestizos con la perspectiva de un renombrado historiador español.

En contraste con la visión mestiza, el principio que caracteriza el mestizaje cultural de Gonzalo Guerrero en la historia de Solís es el "amor de los hijos" presentado con fuertes comentarios de índole moral. Según Solís, Guerrero "se hallaba casado con una india bien acomodada, y tenía en ella tres o cuatro hijos, a cuyo amor atribuía su ceguedad". (Solís no menciona ni la carrera de Gonzalo como militar ni su reticencia a volver por haberse horadado las orejas). Según la interpretación de Solís, Gonzalo Guerrero fingía "estos afectos naturales para no dejar aquella lastimosa comodidad que en sus cortas obligaciones pesaba más que la honra y que la religión".

Al presentar a un Guerrero cínico, falso, que fingía sentimientos de afecto para quedarse en la comodidad de su vida entre los mayas, Solís inadvertidamente revela los antagonismos y la diversificación social que en España y el virreinato novohispano presentaban ya consolidadas las tensiones producidas por el mestizaje.

A pesar de que las comunidades mestizas surgieron muy temprano en las islas antillanas y continuaban expandiéndose durante el desarrollo de los contactos y las conquistas posteriores, Solís (56; lib. 1, cap. 16) afirma sobre Gonzalo Guerrero que "[n]o hallamos que se refiera de otro español en estas conquistas semejante maldad: indigno por cierto de esta memoria que hacemos de su nombre". Consciente del peso que ha tenido en la historia indiana la construcción gomariana y bernaldiana del personaje, lamenta que "no podemos borrar lo que escribieron otros, ni dejan de tener su enseñanza estas miserias a que está sujeta nuestra 
naturaleza, pues se conoce por ellas a lo que puede llegar el hombre, si le deja Dios". A pesar suyo, Solís da constancia de lo intrigante que el relato de Gonzalo Guerrero podría ser para el receptor; testimonia el peligro que percibía en abandonar "honra y religión" para formar una familia mestiza.

\section{UNA LeCtura RETrospectiva: UNA INVESTIGAdora EN AKUMAL}

Al concluir, quisiera volver sobre la estatua de Gonzalo Guerrero para intentar leer desde un imaginario presente los textos que elaboran y consolidan el ícono cultural de Gonzalo Guerrero. Como en los autores del siglo dieciséis, el conjunto escultórico reelabora el ícono con omisiones y supresiones para adaptarlo al presente. ¿Qué tipo de ícono cultural se presenta a la vista de los que llegan a la playa de Akumal en la escultura de Gonzalo Guerrero (véanse figuras 1 y 2)?

Hay tres hijos, la madre desparece en la perspectiva frontal; la noble Xzazil está sentada detrás de su esposo. El visitante que se acerca a la estatua de frente no ve a la princesa cuyas facciones, joyas y vestimenta son vagamente mayas y se perfilan con mayor claridad al aproximarse al conjunto por uno de sus costados. Allí se la encuentra amamatando a su criatura que parece refugiarse bajo su pecho. Estos niños no tienen facciones visiblemente mayas sino que sus atributos parecen provenir del cuerpo paterno.

El propio Gonzalo ocupa el centro del conjunto. Está erguido y orgullosamente recto; tiene horadadas las orejas pero no labradas la nariz ni las mejillas. Lleva pendientes largos en las orejas, un gran collar y brazaletes de señor, un adorno que sujeta su cabello formando una cola, un taparrabo largo y sandalias. Su cabello largo está peinado de tal manera que recuerda los peinados masculinos vistosos encontrados en la iconografia maya precolombina. Lleva una lanza que descansa vagamente inclinada en su mano izquierda y con la mano derecha acaricia la cara sonriente del mayor de sus pequeños hijos.

Anunciada literalmente como "la primera familia de mestizaje nacional" y simbólicamente como la primera familia de la república, la asamblea de los personajes presenta claramente una jerarquía racial y étnica (lo español predomina sobre lo maya), cultural y social (lo europeo sobre lo americano) y de género (el hombre erguido, la mujer sentada y oculta). En esta fórmula escultórica, el carácter de español "indianizado" de Gonzalo se denota en su vestimenta y adornos, particularmente en los pendientes que le cuelgan de las orejas. Su identidad como guerrero se denota en la lanza. Su vida familiar y amor por los hijos se representa en la familia reunida y el gesto amoroso de dejar descansar su mano en la mejilla del hijo como respondiendo a su abrazo. De este modo el escultor Ayala ha reunido los mismos papeles sociales articulados por los antiguos autores: Gonzalo es guerrero, esposo y padre. El problema de la religión desaparece; pertenece a otra época. El problema de la raza se neutraliza y se disuelve en los rasgos de sus cuerpos. Al agregar el casco de Gonzalo, el artista pone de relieve su carácter de ex-conquistador, y la mirada de la hija parece una lectura del pasado, del poder político creado por los españoles y vigente sólo como una huella.

Cuando acababa de presentar en un congreso de la Universidad Autónoma de Yucatán en Mérida mi ponencia "Intérpretes y conquistadores: el mestizaje cultural y la construcción 
narrativa de la figura histórica de Gonzalo Guerrero", ${ }^{16}$ tuve la inquietud de visitar la estatua de Gonzalo en Akumal. Al observarla, comprendí que leía simultáneamente todos esos tiempos y reescrituras de los que había hablado y los veía concentrados en esos volúmenes escultóricos de aparencia inocente. Al mismo tiempo, me di cuenta de que mi ponencia no era sobre el pasado de Yucatán sino sobre su presente y que sólo entonces acababa de reescribirla.

El enigma de la estatua de Gonzalo Guerrero no está en su supuesto propósito de conmemorar el pasado sino en su claro (aunque controvertido) intento-más bien de crear fronteras que cruzarlas - de proyectar un futuro. De igual manera, la relevancia actual del pasado colonial y el deseo de renarrar sus historias no consiste en su capacidad de revelar los secretos de nuestros orígenes sino en responder a nuestras inquietudes acerca del mundo presente.

\section{OBRAS CITADAS}

Aguirre Rosas, Mario. Gonzalo de Guerrero, padre del mestizaje iberoamericano. Prólogo de Alfonso Taracena. México: Jus, 1975.

Alva Ixtlilxochitl, Fernando de. Historia de la nación chichimeca. 1615-25. En Obras históricas, tomo II. Ed. Edmundo O'Gorman. 2 tomos. Serie de historiadores y cronistas de Indias 4. México: Universidad Nacional Autónoma, 1985. 7-263.

Canby, Vincent. "On the Road with Cabeza de Vaca". Reseña de Cabeza de Vaca. Dir. Nicolás Echevarría. Instituto de Cinematografia Mexicanay Televisión Española, 1990. New York Times 23 de marzo de 1991.

Chamberlain, Robert S. The Conquest and Colonization of Yucatan, 1517-1550. Washington: Carnegie Institution of Washington, 1948.

Coleccion de documentos inéditos relativos al descubrimiento, conquista y organización de las antiguas posesiones españolas de América y Oceanía. 42 tomos. Madrid, 186484.

Cortés, Hernán. Cartas de relación. Ed. Ángel Delgado Gómez. Clásicos Castalia 198. Madrid: Castalia, 1993.

Díaz del Castillo, Bernal. Historia de la conquista de la Nueva España, tomo I. 1550s-84. Ed. Carmelo Sáenz de Santa María. 2 tomos. Madrid: Instituto "Gonzalo Fernández de Oviedo", Consejo Superior de Investigaciones Científicas, 1982.

\footnotetext{
${ }^{14}$ Se le conocía a García del Pilar como un hombre sin escrúpulos y se decía que se comportaba como indio (andando "desnudo con su manta y con mastel a manera de indios" y "algunas vezes vestido a manera de yndio de guerra e con plumajes"), haciendo sus bailes y areitos y amansebándose con una mujer india con quien tenía varios hijos ("Probanza" f4r-f14v). Había participado en la conquista de México y había sido notorio por su papel como intérprete en la conquista de Michoacán en 1530-31 y partícipe en la tortura del Cazonçi de Michoacán y luego traidor al declarar como testigo en las pesquisas sobre la muerte del mismo contra su señor Nuño Beltrán de Guzmán (García Icazbalceta xlii-xliv). Guzmán replicó a estos cargos recogiendo los citados testimonios sobre la vida del intérprete entre los indios de Michoacán en una probanza "sobre lo que Pilar dispuso contra el dicho señor gobernador". La coincidencia entre las imágenes de García del Pilar y Gonzalo Guerrero es evidente y la sustitución del nombre de uno por el del otro no sorprende.
} 
Fernández Santos, A. "La condición trágica del descubrimiento y conquista de América". Reseña de Cabeza de Vaca. Dir. Nicolás Echevarría. Instituto de Cinematografía Mexicana y Televisión Española, 1990. El País 25 de febrero de 1991.

García Icazbalceta, Joaquín. Colección de documentos para la historia de México, tomo II. 1866. Biblioteca Porrúa 48. 2 tomos. México: Porrúa 1980.

Gómara, Francisco López de. Historia de las Indias. 1552. Ed. Jorge Gurría Lacroix. Biblioteca Ayacucho 64. Caracas: Biblioteca Ayacucho, 1979.

La conquista de México. 1552. Ed. Jorge Gurría Lacroix. Biblioteca Ayacucho 65. Caracas: Biblioteca Ayacucho, 1979.

Landa, Fr. Diego de. Relación de las cosas de Yucatán. 1566. Ed. Miguel Rivera. Crónicas de América 7. Madrid: Historia-16, 1985.

Lipschutz, Alejandro. "En defensa de Gonzalo Guerrero, marinero de Palos". En Miscelánea de estudios dedicados a Fernando Ortiz, por sus discipulos, cxolegas y amigos, con ocasión de cumplirse sesenta años de la publicación de su primer impreso en Menorca en 1895. Habana: Sociedad Económica de Amigos del País, 1955. 93142.

López de Cogolludo, Fr. Diego. Historia de Yucatán. 1688. Prólogo de J. Ignacio Rubio Mañe. Quinta ed. México: Academia Literaria, 1957.

Martínez, José Luis. Hernán Cortés. México: Universidad Nacional Autónoma y Fondo de Cultura Económica, 1990.

Martínez, José Luis, ed. Documentos cortesianos, tomo I. Sección de obras de historia. 4 tomos. México: Universidad Nacional Autónoma y Fondo de Cultura Económica, 1990.

Martínez Marín, Carlos. "La aculturación indoespañola en la época del descubrimiento de México". Homenaje a Pablo Martínez del Río en el vigésimoquinto aniversario de la primera edición de 'Los origenes americanos'. México: Instituto Nacional de Antropología e Historia, 1961. 401-10.

Muñoz Camargo, Diego. Historia de Tlaxcala. 1576. Ed. Germán Vázquez. Crónicas de América 26. Madrid: Historia-16, 1986.

Oviedo y Valdés, Gonzalo Fernández de. Historia general y natural de las Indias, islas y tierra firme del mar océano. 1525-48. Ed. José Amador de los Ríos. 4 tomos. Madrid: Real Academia de la Historia, 1851-55.

Pastor, Beatriz. Discursos narrativos de la conquista: mitificación y emergencia. [1983]. Segunda ed. Hanover: Ediciones del Norte, 1988.

Prem, Hanns, Berthold Riege, Antje Gunsenheimer, Gabriela Solís. "En torno a Gonzalo Guerrero". Arqueología Mexicana 3:18 (marzo-abril 1996), 4-5.

"Probanza ... hecha ... por parte ... de Nuño de Guzmán ... sobre lo que Pilar dispuso contra el dicho señor governador ... 1532”. Archivo General de Indias. Justicia 229: f1 r-f16r.

San Buenaventura, Fray Joseph de. Historias de la conquista del Mayab, 1511-1697. [1725]. Ed. Gabriela Solís Robleda y Pedro Bracamonte y Sosa. Mérida, Yucatán, México: Universidad Autónoma de Yucatán, 1994.

Solís Robleda, Gabriela y Pedro Bracamonte y Sosa. "Introducción". Historias de la conquista del Mayab. ix-xl. 
Solís y Rivadeneira, Antonio. Historia de la conquista de México, poblacióny progresos de la América Septentrional, conocida por el nombre de Nueva España. [1684]. Ed. Edmundo O'Gorman. Notas de José Valero Silva. Cuarta ed. México: Porrúa, 1985.

Tapia, Andrés de. "Relación hecha por el señor Andrés de Tapia, sobre la conquista de México". En Joaquin García Icazbalceta, ed., Colección de documentos para la historia de México, segundo tomo. 554-94.

Thomas, Hugh. Conquest: Montezuma, Cortés, and the Fall of Old Mexico. New York: Simon and Schuster, 1993.

Torres Ramírez, Bibiano. "La odisea de Gonzalo Guerrero en México". En Actas del Congreso de historia del descubrimiento (1492-1556), tomo II. 4 tomos. Madrid: Real Academia de la Historia y Confederación Española de Cajas de Ahorros, 1992. 369-86.

Tozzer, Alfred M., ed. Landa's Relación de la cosas de Yucatán. Harvard University. Peabody Museum of Archaeology and Ethnology Papers 18. Cambridge, MA: Harvard University, 1941. 


$$
\text { - }
$$

